\title{
Reliability and validity assessment of gastrointestinal dystemperaments questionnaire: a novel scale in Persian traditional medicine
}

\author{
Hamidreza Hoseinzadeh ${ }^{1}$, Ali Taghipour ${ }^{2}$, Mahdi Yousefi ${ }^{3}$, Hamidreza Rostamani $^{1}$
}

${ }^{1}$ Ph.D. Candidate, Department of Persian Medicine, School of Persian and Complementary Medicine, Mashhad University of Medical Science, Mashhad, Iran

${ }^{2}$ Associate Professor of Biostatistics and Epidemiology Department, Health Sciences Research Center, School of Health, Mashhad University of Medical Sciences, Mashhad, Iran

${ }^{3}$ Assistant Professor, Department of Persian Medicine, School of Persian and Complementary Medicine, Mashhad University of Medical Sciences, Mashhad, Iran

Type of article: Original

\begin{abstract}
Background: Development of a questionnaire based on the resources of Persian traditional medicine seems necessary. One of the problems faced by practitioners of traditional medicine is the different opinions regarding the diagnosis of general temperament or temperament of member. One of the reasons is the lack of validity tools, and it has led to difficulties in training the student of traditional medicine and the treatment of patients. The differences in the detection methods, have given rise to several treatment methods.

Objective: The present study aimed to develop a questionnaire and standard software for diagnosis of gastrointestinal dystemperaments.

Methods: The present research is a tool developing study which included 8 stages of developing the items, determining the statements based on items, assessing the face validity, assessing the content validity, assessing the reliability, rating the items, developing a software for calculation of the total score of the questionnaire named GDS v.1.1, and evaluating the concurrent validity using statistical tests including Cronbach's alpha coefficient, Cohen's kappa coefficient.

Results: Based on the results, 112 notes including 62 symptoms were extracted from resources, and 58 items were obtained from in-person interview sessions with a panel of experts. A statement was selected for each item and, after merging a number of statements, a total of 49 statements were finally obtained. By calculating the score of statement impact and determining the content validity, respectively, 6 and 10 other items were removed from the list of statements. Standardized Cronbach's alpha for this questionnaire was obtained 0.795 and its concurrent validity was equal to 0.8 .

Conclusion: A quantitative tool was developed for diagnosis and examination of gastrointestinal dystemperaments. The developed questionnaire is adequately reliable and valid for this purpose. In addition, the software can be used for clinical diagnosis.

Keywords: Traditional medicine; Questionnaire; Gastrointestinal Functional diseases, Dyspepsia
\end{abstract}

\section{Introduction}

\subsection{Background}

In modern medicine, it is well known that healthy individuals have different physical and mental characteristics. Gastrointestinal diseases are the most common reasons for patients visiting medical centers. For the diagnosis of gastrointestinal diseases in conventional medicine, some tools such as endoscopy and radiography and laboratory methods including serological tests are usually used. Another tool that is used in functional gastrointestinal diseases involves clinical criteria and indicators based on medical history and symptoms, referred to as the questionnaire with specific criteria. Manning et al. in 1978, proposed the Manning Criteria for the diagnosis of IBS. The Roman

\section{Corresponding author:}

Hamidreza Rostamani, Department of Persian Medicine, School of Persian and Complementary Medicine, Mashhad University of Medical Sciences.

Tel: +98.5138829279, Fax: +98.09111733180, Email: RostamaniM911@mums.ac.ir

Received: May 06, 2017, Accepted: July 15, 2017, Published: February 2018

iThenticate screening: June 29, 2017, English editing: December 12, 2017, Quality control: January 12, 2018

(C) 2018 The Authors. This is an open access article under the terms of the Creative Commons Attribution-NonCommercialNoDerivs License, which permits use and distribution in any medium, provided the original work is properly cited, the use is non-commercial and no modifications or adaptations are made. 
Coordinating Committee, based in Rome, Italy, elicited and organized the views and comments of experts and researchers on functional gastrointestinal diseases using Delphi method, and later, issued the IBS diagnostic criteria in 1992 and the Functional gastrointestinal disorders (FGIDs) diagnostic criteria in 1994 within Rome I Criteria. This was revised in 1999 and reissued under the title of Rome II Criteria and later as Rome III Criteria in 2006. For the development of the latter, the views and comments of 87 experts in 14 committees consisting of 18 countries were elicited. The Rome Criteria is mainly based on clinical symptoms and medical History of symptoms for most functional gastrointestinal diseases $(1,2)$. One of the medical and health care systems in the world is Greek medicine or Unani Medicine which has its roots in the wisdom-based Persian medicine (3), and Avicenna's The Canon of Medicine as one of its main resources $(4,5)$. Persian Traditional Medicine is a comprehensive medical school which involves methods of diagnosis, etiology, and treatment. To maintain health and treat disease, this medical school, backed by thousands of years of science and experiments of Persians and other nations, emphasizes interpersonal differences (traditionally named Mezaj meaning temperament) (6). According to the World Health Organization, traditional medicine is the sum total of the knowledge, skills, and practices based on the theories, beliefs, and experiences indigenous to different cultures, whether explicable or not, used in the maintenance of health as well as in the prevention, diagnosis, improvement or treatment of physical and mental illness (7). In Persian traditional medicine, the medical history and examination tools are used to diagnose diseases (8). Temperament (Mezaj) is one of the fundamental concepts in Persian traditional medicine. Temperament is a general term implying the qualitative and quantitative state of an organ or the whole body, taking shape from a combination of the four elements. School of Persian traditional medicine considers a general temperament for the whole body and a specific one for each organ. Every organ can normally function in the case of having a natural temperament. Dystemperaments (traditionally called Suemezaj) occur when the natural temperament of an organ is disturbed for any reason. Depending on clinical symptoms, there are different types of dystemperament (8). In recent years, many studies have been conducted on the development of questionnaires based on foundations and principles of Persian traditional medicine (9-11).

\subsection{Objectives}

This study was the first research that carried out the preliminary steps of developing an objective and easily applied scale for Mezaj determination in PTM. We developed a preliminary self-administered questionnaire according to indices, and assessed its reliability and validity. The review of other questionnaires also showed that some of these questionnaires have been developed for healthy people and cannot be applied to patients. Some other questionnaires measure only the general temperament of patients and are not sensitive to the disease or dystemperament of a specific body organ. Moreover, some of these questionnaires have never gone through expected stages of validation and standardization. The above-mentioned shortcomings, on the one hand, and the importance and prevalence of the temperaments of the gastrointestinal tract, on the other hand, necessitate the development of a specific questionnaire based on texts of Persian traditional medicine for gastrointestinal diseases. Therefore, the present study aims to develop a questionnaire and software for determining gastrointestinal dystemperaments using a rigorous, step-bystep scientific method.

\section{Material and Methods}

The procedure of this cross-sectional study included four steps: Item Generation, Recruitment of Participants, Validity Process and Scoring. The present research was an applied and descriptive survey which aimed to develop a specialized tool with a Mixed based approach (a combination of Problem-based/ Profession based) for the diagnosis of gastrointestinal disorders based on paradigms of Persian traditional medicine. For this purpose, a questionnaire was developed for determining gastrointestinal dystemperaments and its validity and reliability were evaluated. Steps taken were as follows:

\subsection{Stage 1-2: Item development (Item generation) and determining the questionnaire statements}

For the development of the items, pool resources of Persian traditional medicine were selected using the criterionbased conceptual-deductive model. Resources were selected based on the following criteria:

- Resources from different periods of medicine history.

- Available resources in Arabic.

- The dictionaries used included Arabic and Farsi.

- Expert panel approves the selected criteria and resources.

Based on the above-mentioned criteria, 11 books were selected, including:

- Firdous al-Hikmah (Abu al-Hasan Ali ibn Sahl Rabban al-Tabari, $2^{\text {nd }}$ and $3^{\text {rd }}$ centuries AH),

- Kitāb Kāmil al-Sanā'a al-Tibbiyya (Ali ibn al-'Abbas al-Majusi $4^{\text {th }}$ century AH), 
- Hidayat al-Muta allemin Fi al-Tibb (Al-Akhawyni Bokhari,4 $4^{\text {th }}$ century AH),

- Al-Qanun fi Tibb ("The Canon of Medicine") of Avicenna ( $4^{\text {th }}$ and $5^{\text {th }}$ centuries AH),

- Zakhireye Khwarazmshahi (Ismail Gorgani , $5^{\text {th }}$ and 6 th centuries AH),

- Teb Al-Akbar (Muhammad Akbar Arzani ,12 ${ }^{\text {th }}$ century AH),

- Moalejate Aghili (Mohammad Hossein Aghili Khorasani ,12th century AH)

- Kholasat Al- Hekmah (Mohammad Hossein Aghili Khorasani ,12th century AH)

- Eksir Azam (Mohammad Azam Khan, $13^{\text {th }}$ century AH),

- Kitab Al-Ma'a (Abu Mohammed Abdellah Ibn Mohammed Al-Azdi)

- Jawahir al-lughah wa-Bahr al-jawahir (Muhammad ibn Yusuf al-Harawi)

Members of the expert panel were selected based on the following criteria:

- Having a Ph.D. in Persian Traditional Medicine.

- Residents of Traditional Medicine who have passed three years of their education.

After the initial selection of resources, symptoms of gastrointestinal diseases, with a focus on dystemperaments, were extracted. Based on the data saturation principle, the books of any period were reviewed until data saturation in terms of concepts and symptoms was achieved. To sum up the differences between the findings and extract the initial themes, interview sessions and the panel of experts were held, and finally, a bank of items was developed. One statement was assigned to each of the items resulting from the first stage. Some items such as risk factors or mitigating factors were mentioned in a single question with a few concrete examples. For example, if the patient suffers from nausea, all foods and drinks that would exacerbate this symptom were included in a single question. Choices and scales varied depending on the item type. For instance, for a patient's mouth taste in a fasting state, the options bitter, salty, tasteless, sweet, and sour were used. Five-point Likert scale was used for items that there was a need to determine their frequency or intensity. Some of the items can be responded to by patients, while the result of the medical examination is decisive for others. For example, in terms of examination of the patient's abdomen or tongue color, the data entry criterion is the result of the physician's examination. The stage 2 , included determining the questionnaire statements based on items obtained in the first stage.

\subsection{Stage 3: Assessment of the face validity of statements}

For this purpose, 15 patients with digestive problems who visited the gastroenterology clinic of Ghaem Hospital of Mashhad University of Medical Sciences were selected to assess the statements in terms of the level of difficulty, appropriateness, and ambiguity. To reduce the number of statements, the impact factor method was used and those with an impact factor of greater than 1.5 were selected for further analysis.

\subsection{Stage 4: Assessment of the content validity of statements}

For this purpose, 5 graduates and $4 \mathrm{Ph} . \mathrm{D}$. students of Traditional Medicine, and also one epidemiologist were asked to evaluate and make their comments on the statements in terms of grammar, vocabulary, importance, significance, and Item allocation. Then, content validity ratio (CVR) and content validity index (CVI) were calculated. To assess these indicators, written comments of 14 graduates and Ph.D. students of Traditional Medicine were collected through special forms. According to Lawshe Table and considering the number of experts in the panel, the statements with a CVR of higher than 0.51 were retained (12). The selection of items was also based on a CVI of at least 0.7 (13). The same procedure was done for calculation of CVI.

\subsection{Stage 5: Assessment of the reliability}

To measure the internal consistency, Cronbach's alpha coefficient was used and values greater than 0.7 were considered acceptable $(14,15)$. To evaluate this criterion, the questionnaire was filled out by 30 patients with digestive disorders visited the gastroenterology clinic of Ghaem Hospital and Imam Reza Hospital of Mashhad University of Medical Sciences.

\subsection{Stage 6: Items rating}

To determine the numerical value of each item and the relevant scales, considering the structure and classes derived from the fifth stage, the views and comments of experts and scholars were elicited to be the basis for rating the items and their scales.

\subsection{Stage 7: Development of a software for calculation of the questionnaire total score}

To determine the questionnaire total score on each of the four temperaments, software was developed which supplies the therapist with the final score of the examinees on each of the four qualities. This software was called gastrointestinal dystemperament scoring v.1.1. 


\subsection{Stage 8: Assessment of the concurrent validity}

In order to compare the results of determining gastrointestinal dystemperaments obtained from the software and those of in-person oral medical history elicitation, 10 patients were examined by two experts of traditional medicine, who were not involved in the development of the questionnaire, using the conventional non-survey method. Then, they were again examined for gastrointestinal dystemperaments using the questionnaire developed in this study. Finally, the concurrence between the results of experts and the questionnaire was assessed using Cohen's kappa coefficient (16). CVR and CVI were calculated using Excel 2010 and other statistical tests were performed in SPSS. The present study was approved by the Ethics Committee (IRMUMS.REC.1394.393). After briefing the participants on the research purpose and procedure, a written informed consent was obtained from them. They were assured that their personal information will be kept confidential.

\section{Results}

In the literature review, 112 notes including 62 symptoms were extracted $(8,17-27)$. The theme of these notes was summarized in 17 notes during 10 interviews and 2 sessions of panels of experts. As a result, the initial bank of items included 58 items consisting of clinical symptoms ranging from complaints or findings of the physician during examination or recording the patient's medical history. After reviewing all these items, 49 statements were developed. Even the ambiguity of some of the terminology of traditional medicine and based on the feedback received from patients, statements were rewritten in a simple language, so that both their scientific and technical nature were preserved and they were understandable to patients. By calculating the impact factor, 6 statements were eliminated and the rest were assessed for content validity. Based on the criteria outlined in the CVR and CVI, the experts responded to relevant questions regarding each item. The results obtained from the calculation of these indices have been shown in Table1. The items that fail to earn the minimum passing score on these indices were those which contained objective symptoms, such as pulse, body appearance, and external soft edema. Another part of the eliminated statements included those which were difficult to be diagnosed by patients or the physician due to the impact of confounding factors, such as complexion, stomach tenderness, and volume of stool. In this stage, 10 other items were removed from the list of statements.

Table 1. Items, Content validity index (CVI), Content validity ratio (CVR)

\begin{tabular}{|c|c|c|c|c|}
\hline Items (The item statement) & CVR & CVI & $\begin{array}{l}\text { Cronbach's } \\
\text { Alpha }\end{array}$ & Results \\
\hline How is the taste of the patient's mouth when fasting? & 1 & 1 & 0.762 & Accept \\
\hline How is the status of the patient's mouth dryness and humidity? & 1 & 0.92 & 0.754 & Accept \\
\hline Do you have drooling during sleep? & 1 & 0.92 & 0.738 & Accept \\
\hline How is your appetite, most days? & 1 & 0.78 & 0.766 & Accept \\
\hline Do you get nauseated? & 0.71 & 0.78 & 0.750 & Accept \\
\hline Taking which foods or drinks exacerbates this condition? & 0.71 & 0.78 & 0.768 & Accept \\
\hline Taking which foods or drinks improves this condition? & 0.71 & 0.78 & 0.769 & Accept \\
\hline Do you suffer from vomiting? & 0.55 & 0.78 & 0.756 & Accept \\
\hline Taking which foods or drinks exacerbates this condition? & 0.55 & 0.75 & 0.768 & Accept \\
\hline Taking which foods or drinks improves this condition? & 0.55 & 0.75 & 0.766 & Accept \\
\hline Do you suffer from heartburn? & 1 & 1 & 0.804 & Accept \\
\hline Taking which foods or drinks exacerbates this condition? & 1 & 0.9 & 0.782 & Accept \\
\hline Taking which foods or drinks improves this condition? & 1 & 0.9 & 0.778 & Accept \\
\hline Do you suffer from acid belching after having a meal? & 1 & 0.85 & 0.746 & Accept \\
\hline Taking which foods or drinks exacerbates this condition? & 0.85 & 0.85 & 0.764 & Accept \\
\hline Taking which foods or drinks improves this condition? & 0.57 & 0.85 & 0.766 & Accept \\
\hline $\begin{array}{l}\text { Do you normally feel thirsty during the day? (apart from the cases resulted from } \\
\text { the extreme heat and high activity) }\end{array}$ & 0.71 & 0.85 & 0.823 & Accept \\
\hline Do you have a feeling of heaviness and fullness after having a meal? & 1 & 1 & 0.746 & Accept \\
\hline Do you suffer from gastric traction after having a meal? & 0.71 & 0.8 & 0.744 & Accept \\
\hline $\begin{array}{l}\text { If the answer to above question is "Yes", which food causes this condition more } \\
\text { frequently? }\end{array}$ & 0.71 & 0.8 & 0.762 & Accept \\
\hline $\begin{array}{l}\text { Do you have a feeling of lightness and comfort in the stomach (stomach } \\
\text { emptiness) a few hours after having a regular meal with normal volume? }\end{array}$ & 0.71 & 0.8 & 0.745 & Accept \\
\hline How many hours after having a meal do you feel you need to defecate? & 0.57 & 0.85 & 0.765 & Accept \\
\hline Do you suffer from bloating in the stomach after having a meal? & 1 & 0.85 & 0.747 & Accept \\
\hline
\end{tabular}




\begin{tabular}{|l|l|l|l|l|}
\hline Taking which foods or drinks exacerbates this condition? & 1 & 0.85 & 0.762 & Accept \\
\hline Taking which foods or drinks improves or reduces this condition? & 0.85 & 0.85 & 0.768 & Accept \\
\hline Can you tolerate starvation? & 0.57 & 0.85 & 0.752 & Accept \\
\hline What kind foods and drinks do you often feel like? & 1 & 0.85 & 0.762 & Accept \\
\hline Do you suffer from bloating in the intestine after having a meal? & 1 & 1 & 0.762 & Accept \\
\hline Have you ever noticed undigested food in your stool? (as pieces of eaten food) & 0.57 & 0.85 & 0.761 & Accept \\
\hline How is the status of your defecation? & 1 & 1 & 0.770 & Accept \\
\hline How is the consistency of your stool? & 0.71 & 0.85 & 0.787 & Accept \\
\hline How much is your stool volume? & 0.48 & & & Reject \\
\hline Is the patient's stool bloated (swollen)? & 0.24 & & & \\
\hline Pulse length & 0 & & & Reject \\
\hline Pulse width & 0 & & & Reject \\
\hline Pulse frequency & 0 & & & Reject \\
\hline Pulse consistency & 0 & & & Reject \\
\hline Body appearance & 0.28 & & & Reject \\
\hline Stomach tenderness & 0.49 & & & Reject \\
\hline Complexion & 0.14 & & & Reject \\
\hline Does the patient show any symptom of unusual swelling? & 0.38 & & & Reject \\
\hline Abdomen percussion (abdomen examination) & 0.85 & 0.85 & 0.801 & Reject \\
\hline What is the color of patient's tongue? & 0.85 & 0.85 & 0.793 & Accept \\
\hline
\end{tabular}

The results obtained from the assessment of internal consistency using Cronbach's alpha coefficient have been calculated. According to the results, all the items have obtained an acceptable score. The Standardized and nonstandardized alpha coefficients for this questionnaire were 0.795 and 0.772 , respectively. These values represent the acceptable reliability of this questionnaire. To calculate the final score of the patient on the four qualities, the numerical value of the items was determined as follows: A) The range of scores for the items for which Likert scale was used, was determined to be between 1 and 10. For example, for drooling during sleeping, the choices were determined to be "No", "Never", "Sometimes", "Often", and "Always", with scores of 1, 3, 5, 8, and 10, respectively. B) The coefficient and weight of categories and subcategories and their relevant items are not the same. To decide in this regard, the panel of experts was used. Each of the experts weighted the categories, subcategories, and items based on the expert views, clarification of texts, and clinical experiences. For the sake of unity, the total score of patients was assumed to be 100 . Then, based on the categories and subcategories of the fifth stage, the significance of categories was determined by assigning them the scores, the sum of which was 100 . Finally, the scores announced by the experts were the basis for rating (Figure 1).

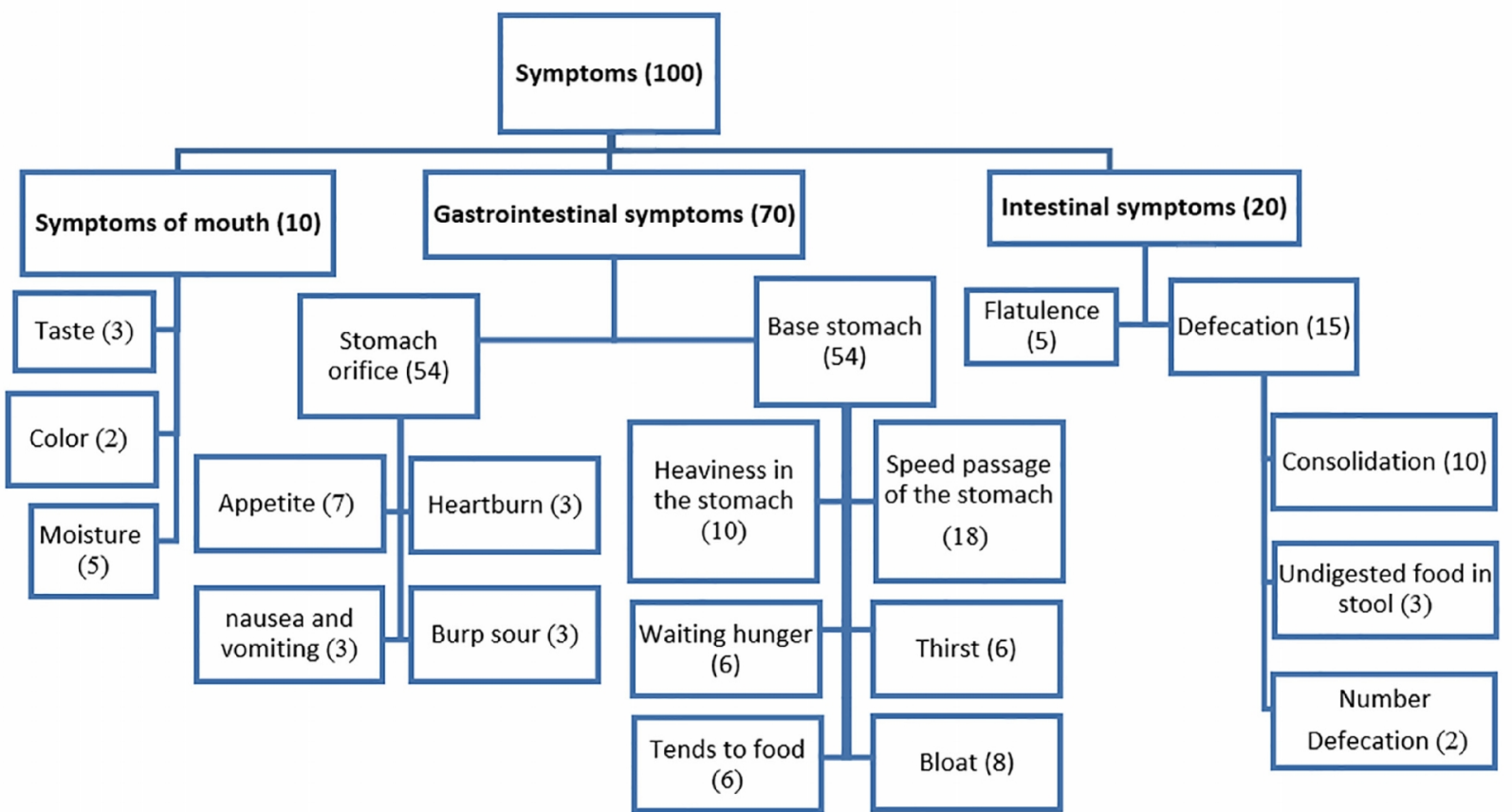

Figure 1. Diagram classification of symptoms and their relative weights 
Scores and coefficients of each item were applied to the developed software. Initially, Excel was used to assess how to calculate the final score. After approval of the final development, specialized software was used. In the final assessment of the reliability of results, the final comments of two traditional medicine experts on the type of gastrointestinal dystemperament of 10 patients were compared with the software evaluation. The concurrence of results was assessed using Cohen's kappa coefficient (Table 2).

Table 2. The agreement based on the kappa coefficient

\begin{tabular}{|l|l|}
\hline Index & Kappa coefficient \\
\hline Heat & 0.83 \\
\hline Cold & 0.95 \\
\hline Moisture & 0.92 \\
\hline Dryness & 0.80 \\
\hline
\end{tabular}

\section{Discussion}

The issue of temperament is one of the principles of Persian medicine. In conventional medicine, no direct equivalent to this concept can be found in conventional medicine. However, individual differences in gene level to active metabolites in the cell are referred to as genomics, proteomics, and metabolomics in new studies. Therefore, a relation can be traced between these sciences and temperament $(28,29)$. Scholars of Persian traditional medicine considered a specific temperament for each of the body organs as well as for each person, classified as organ temperament and individual temperament in one of the classifications. Brain, liver, and heart, referred to as the head body organs, are three decisive organs in the temperament of other parts and the general temperament of individuals (30). In fact, it is the interaction between the temperaments of these three organs that influences the temperaments of other body organs. If living conditions including nutrition, exercise, sleep, and mental action of a person are in accordance with nature, it is expected that the resultant of the organ temperament of the head body organs and other organs be consistent with the general temperament. This means that if one's general temperament is warm, the temperament of the gastrointestinal tract, brain, heart, liver, spleen, kidneys, and other organs is inclined to warmth. Non-codified clinical experience suggests that in the current situation there is an increasing contribution of chemicals in food and pharmaceutical products, and unfavorable conditions of life and psychological problems, different body organs are influenced by specific confounding variables which predispose them to a variety of dystemperaments. In this case, the resultant of temperaments of different organs may be inclined to two conflicting qualities. For instance, the gastrointestinal tract may show symptoms of coldness, while there are some signs of warmth in the brain at the same time. In other words, in the absence of sufficient experience in differentiating causes from effects, the therapist may be confused in diagnosing the temperament or dystemperament of an organ and general temperament of a patient. This confusion also strongly affects the treatment protocol and sometimes leads to the administration of diametrically opposing drugs (in terms of the four qualities). Hence, diagnosis of temperaments and dystemperaments of body organs is of greater importance in today's life. Some efforts are underway to develop a standard measure of temperament which indicates the attention paid to the significance of this issue by researchers and therapists. Salmannejad et al. are developing and validating a self-report questionnaire for determining the temperaments in the age group 40-60. This questionnaire can be applied for determining the general temperament only in healthy individuals (30). Shahabi et al., in their study, used a 100-item questionnaire for determining the temperaments related to symptoms of the four temperaments domination. Some items of the questionnaire do not exist in traditional medicine resources. In addition, the authors have not described the process of development and validation. The participants in this study were, by default, assigned to one of the four categories of blood, yellow bile, black bile, and phlegm, and it is not clear whether these refer to the temperament or dystemperament of individuals. On the other hand, no column was dedicated to moderate individuals or those with the domination of one quality (31). Nasseri et al. proposed a 32-item questionnaire for the measurement of the four qualities (cold, warm, dry, and moist). Although this questionnaire is simple and smooth in items and statements and is based on the original sources of traditional medicine, no evidence of its validity and reliability has been provided by authors (32).

Mozaffarpur et al. used two questionnaires for determining the general temperament and the gastrointestinal tract temperament of patients participated in a clinical study, without mentioning the process of their development and validation (33). Roshandel et al. (2015) applied two 26-item and 56-item questionnaires for determining the natural temperament and transverse temperament. The content validity of these questionnaires was approved by 5 experts of traditional medicine, and their reliability was assessed through a pilot study on 15 patients. Some items of these questionnaires such as nasal fins status, lip shape, lip size, and mouth shape were not consistent with the resources of traditional medicine. All participants were assigned to one of the four temperaments of blood, yellow bile, black 
bile, and phlegm, representing the temperament domination, and could not be applied to healthy individuals. In addition, the status of individuals with moderate temperament and those with the domination of one quality is not known in these questionnaires (34). Ahmadi et al. (2014) developed a 48-item questionnaire for the assessment of nature temperament which was evaluated by a panel of experts consisting of traditional medicine, epidemiology, nutrition, and dermatology experts. The items were not mentioned in their paper. Most questions were related to childhood conditions, and a number of respondents were not able to remember childhood conditions. It seems that this questionnaire has been developed to be applied to healthy individuals (35). The above analytic review shows that each of the developed tools has their own strengths and weaknesses. One of their common weaknesses is that organ temperament has not been taken into account. In addition, the materials and methods have not been stated in a methodological way. The questionnaire developed in the present study is based on organ temperament, the experts panel was used in its development, its statistical analysis was performed under the supervision of a statistics experts and an epidemiologist, the items bank was extracted from the authentic Persian traditional medicine, and the end result is developed in the form of software for the ease of therapists. In assessing the content validity, pulse, stomach and gastrointestinal tract tenderness, stool volume, complexion, and agitation gained the lowest score. This can be caused by the following: Diagnosis of pulse indicators such as tenderness, strength, speed, length, height, and so on does not have a special position in everyday clinical activities, and considering them requires great skill and spending sufficient time. Pulse parameters are highly affected by so many factors (confounding variables) that it is difficult to make an association between them and the gastrointestinal tract temperament. Rather than representing the gastrointestinal tract temperament, pulse is an indicator of the heart temperament. Therefore, despite the emphasis of traditional medicine texts on pulse-related parameters in gastrointestinal diseases, this indicator did not gain the passing grade to be included in the questionnaire. Another item was stomach and the gastrointestinal tract tenderness. Although this item attracted the attention of traditional medicine experts compared to those related to pulse, complexion, and stool volume, it did not gain the passing grade with regard to the number of experts and Lawshe Table. Two relatively specific items for the gastrointestinal tract (i.e. stool volume and bloated stool) did not gain the passing grade. This may be due to the difficulty of diagnosing this symptom for patients, especially in the case of bulky, bloated stool. Similarly, general symptoms of complexion and external soft edema did not gain the minimum acceptable score. One of the reasons for this can be the relationship of these symptoms with the liver and its dystemperaments, according to experts. In the assessment of the content validity in the present study, indicators related to the mouth including tongue color, mouth taste, and drooling were among the symptoms which were approved by experts, although they were apparently not related to the stomach and intestine. Therefore, they were included in the questionnaire for the diagnosis of the gastrointestinal tract dystemperaments. The small number of specialists and graduates of traditional medicine and patients was one of the limitations of the questionnaire development process. Since this questionnaire did not aim to diagnose the gastrointestinal diseases, many of the patients visiting the gastroenterology clinic who suffered from organic diseases such as peptic ulcers, inflammatory bowel disease, hemorrhoids, intestinal polyposis, and gastrointestinal tract malignancies were not included in the study. This reduced the number of patients filling out the developed questionnaire. The purpose of this questionnaire was to determine different types of dystemperament of the gastrointestinal tract. Hence, other symptoms of gastrointestinal diseases were excluded from the items bank. The authors hope to resolve the limitations as much as possible in next versions of this software. In this study there are some limitation facing researchers, including the inadequacy of traditional medicine specialists. By inviting a number of experts from different cities as well as the participation of several senior Ph.D. students, the problem was solved. Another limitation of the study was the different opinions of the experts on some of the items, which were solved by using statistical methods. Moreover, a joint meeting was held to discuss the items in order to reach a relative agreement regarding the discussed items. In this study the first questionnaire of determination temperament of one member with statistical and scientific process is developed. It is suggested to perform future studies with more samples taken from patients and practitioners of traditional medicine. A member temperament questionnaire with statistical process has been performed for the first time, and its application will be facilitated through software development.

\section{Conclusions}

A questionnaire was developed in this study for the measurement of gastrointestinal dystemperaments based on the signs and symptoms listed on the main sources of Persian traditional medicine and eliciting the views and comments of the panel of experts and Ph.D. students of traditional medicine. Its reliability and validity were assessed using a different method. This questionnaire can be helpful in the diagnosis of the temperaments and dystemperaments of the gastrointestinal tract as well as follow-up and evaluation of treatment outcomes. 


\section{Acknowledgments:}

The present study was extracted from a Ph.D. thesis in Persian Traditional Medicine registered under the code 931557 in Mashhad University of Medical Sciences. The authors would like to thank the members of the experts panel: Dr. Khodadoust from Shahid Beheshti University of Medical Sciences, Dr. Abbasian from Tehran University of Medical Sciences, Dr. Motevaseliyan, Dr. Tavakoli, Dr. Feizabadi, and Dr. Anoushirvani from Mashhad University of Medical Sciences; PhD assistants of Traditional Medicine: Dr. Jafarnejad, Dr. Ghorbanzadeh, Dr. Mehri, Dr. Ghayour, Dr, Rostamani, Dr. Tavassoli, Dr. Gholampour, Dr. Eslami, Dr. Mohammadzadeh, Dr. Naghedi, Dr. Delshad, Dr. Mahjour, and Dr. Mahboub; Mr. Esmaeilnia, and the staff of the gastroenterology clinic of Ghaem Hospital and Imam Reza Hospital of Mashhad and Research Department of Mashhad University of Medical Sciences who helped us in this research.

\section{Conflict of Interest:}

There is no conflict of interest to be declared.

Authors' contributions:

All authors contributed to this project and article equally. All authors read and approved the final manuscript.

\section{References:}

1) Thompson WG, Longstreth GF, Drossman DA, Heaton KW, Irvine EJ, Müller-Lissner SA. Functional bowel disorders and functional abdominal painGut. 1999; 45 Suppl 2: II43-7. PMID: 10457044, PMCID: PMC1766683.

2) Longstreth GF, Thompson WG, Chey WD, Houghton LA, Mearin F, Spiller RC. Functional bowel disorders. Gastroenterology. 2006; 130(5): 1480-91. doi: 10.1053/j.gastro.2005.11.061. PMID: 16678561.

3) Kasper Braunwald Fauci and Hausa Longo Jameson. Harrison's Principles of Internal Medicine, 17th Edition Mcgraw Hill medical publishing division London. 2008.

4) Syed Zillur Rahman. Unani Medicine in India during 1901-1947. New Delhi. 1994; 13(1): $97-112$.

5) Syed Zillur Rahman. Arab Medicine during the Ages. New Delhi. 1996; 14(1-2): 1-39.

6) Borowitz SM, Cox DJ, Tam A, Ritterband LM, Sutphen JL, Penberthy JK. Precipitants of constipation during early childhood. J Am Board Fam Pract. 2003; 16(3): 213-8. doi: 10.3122/jabfm.16.3.213.

7) PMID: 12755248.

8) World Health Organization. National Policy on Traditional Medicine and Regulation of Herbal Medicines: Report of a WHO Global Survey. Geneva, Switzerland: World Health Organization; 2005.

9) Aghili Khorasani MH. Kholassat Al-Hekmah (The Principals of Traditional Persian Medicine). 1 st ed. Qom: Esmaeilian; 1385: 474-81, 853-63.

10) Mojahedi M, Naseri M, Majdzadeh R, Keshavarz M, Ebadini M, Nazem E, et al. Reliability and Validity Assessment of Mezaj Questionnaire: A Novel Self-report Scale in Persian Traditional Medicine. Iran Red Crescent Med J. 2014; 16(3): e15924. doi: 10.5812/ircmj.15924. PMID: 24829785, PMCID: PMC4005447.

11) Yousefifard M. Determining the relationship between hot and cold temperament with blood, biochemical, cardiovascular and respiratory indicators in students of Tehran University of Medical Sciences. Tehran: Department of Physiology, Tehran University of Medical Sciences, 2010.

12) Yousefi M, Vaez Mahdavi MR, Hosseini SM, Bahrami A, Davati A, Kamalinejad M, et al. Clinical Evaluation of Commiphora Mukul, a Botanical resin, in the Management of Hemorrhoids: A randomized controlled trial. Pharmacogn Mag. 2013; 9(36): 350-6. doi: 10.4103/0973-1296.117832. PMID: 24124288, PMCID: PMC3793341.

13) Lawshe CH. A quantitative approach to content validity. Personnel Psychology. 1975; 28: 563-75. doi: 10.1111/j.1744-6570.1975.tb01393.x.

14) Hyrkäs K, Appelqvist-Schmidlechner K, Oksa L. Validating on Instrument for Clinical Supervision using an Expert Panel. Int J Nurs Stud. 2003; 40(6): 619-25. doi: 10.1016/S0020-7489(03)00036-1. PMID: 12834927.

15) Munro BH. Statistical methods for health care research. 4th Edition, Philadelphia: Lippincott, Williams \& Wilkins; 2005.

16) Bland JM, Atman DG. Statistic Note: Cronbach Alpha. BMJ (Clinical research ed.) 1997; (7080): $314-572$.

17) Fleiss JL, Levin B, Paik MC. The measurement of interrater agreement. Statistical methods for rates and proportions. 1981; 2: 212-36. doi: 10.1002/0471445428.ch18.

18) Aghili SMH, Aghiil Treatments. Institute of Studies in Medical History, Islamic and Complementary Medicine. 2008. 
19) Jorjani SEi. Al - Aghraz al - Tibbia val Mabahess al - Alaiia (Medical Goals and Allaii's Discussions). 2nd ed. Tehran: University of Tehran Press; 1388; 1: 218-20.

20) Aviccena. Al-Qanun fi al-Tibb. Beirut: Darul Fikir; 2005.

21) Arzani MA. Tibb al-Akbar (Akbar's Medicine). Qom: Jalaledin; 1387; 2(1): 843.

22) Tabari A. Firdous al-Hikmah.Translated by Madani A, Broujerdi A. Tehran: Mehramin; 2008.

23) Ahvazi A. Kamil al-Sanate al-Tebie. Translated by Ghaffari MK. Tehran: The institute of Islamic Studies; University of Tehran; 2009.

24) Akhawayni Bukhari. Hidayat al-Muta'allimin fit-Tib. Second ed. Mashhad: Mashhad University Press; 1344: 171-8.

25) Jorjani SE. zakhireh kharazmshahi. Facsimile edition. Tehran: Saedy Sirjani, Ali Akbar; 1355: 153-6.

26) Azam Khan M, Aksir A. Institute of Medicine Studies and Islamic medicine press, Tehran. 2004.

27) Heravi M, Bahr-Al-Javaher. Revival Institute for Natural Medicine. Institute of Studies in Medical History, Islamic and Complementary Medicine. 2008.

28) Alazdi A, Al Maa. Correction and research: Hamoudi HH. Institute of Studies in Medical History, Islamic and Complementary Medicine. 2008.

29) Hassan R, Mehrdad K, Mohieddin J. Proteomics of hot-wet and cold-dry temperaments proposed in Persian traditional medicine: a Network based Study. Available From: www.nature.com/scientificreports.

30) Jafari M, Rezadoost H, Karimi M, Mirzaie M, Rezaie-Tavirani M, Khodabandeh M, et al. Proteomics and Traditional Medicine: New Aspect in Explanation of temperament. Forsch Komplementmed. 2014; 21(4): 250-3. doi: 10.1159/000366118. PMID: 25231567.

31) http://pajouhan.mubabol.ac.ir/webreport/view.action? webreport code $=1000 \&$ masterCode $=11002921 \#$

32) Shahabi SH, Zahir MH, Mahdavi M, Dezfuli M, Torabi M, Naseri M. Evaluation of the neuroendocrine system and cytokine pattern in people with hot and cold temperament. Physiology and pharmacology. 2007; 11(1): 51-9.

33) Naseri M. The school of traditional Persian medicine: the definition, origin and advantages. Iran $J$ Pharmaceut Res. 2010; 3(2): 20.

34) Mozafarpour SA. Determining the effect of Cassia in children functional constipation. Tehran: Department of Traditional Medicine, Shahed University; 2012.

35) Roshandel HR, Ghadimi F, Alizadeh M. Developing and evaluation the reliability and validity of structured questionnaire for determining constitutional and adventitious temperament. Journal of Islamic and Iranian Traditional Medicine. 2016; 6(1): 23-42.

36) Ahmadi M, Javadi M, Barikani A, Beheshti A, Ansaripour M. Determining the reliability and validity of questionnaire for assessment of constitutional temperament. Journal of Islamic and Iranian Traditional Medicine. 2015; 5(1): 34-40. 